\title{
RAISING ENGINEERING STUDENTS'AWARENESS AS REGARDS THE IMPORTANCE OF IMPROVING THEIR PROFICIENCY IN ENGLISH
}

\author{
Simona Abrudan Caciora, Amalia Sturza, Anamaria Supuran
}

University of Oradea, Romania

\begin{abstract}
This research paper presents the results obtained after analysing the answers given by a number of 170 engineering students to questions referring to the current role of English, both in engineering education and in engineers' professional activity, especially when that activity is carried out in multinational companies. In addition, it emphasizes the importance of presenting students, during the early stages of their academic education, with the advantages provided by a good command of the English language. First, because employers in the field of engineering, especially those representing multinational companies (and such multinational companies are present in Oradea) need employees with a good grasp of English. Second, because academic education often involves the use of English for conducting research and/or for presenting the results of research.
\end{abstract}

Key words: language skills, engineering students, questionnaire, multinational companies, acquiring language skills

\section{INTRODUCTION ENGLISH AS A GLOBAL LANGUAGE AND THE IMPORTANCE OF TEACHING IT IN UNIVERSITIES - PARTICULAR CASE OF ENGINEERING STUDENTS}

Nowadays, English has become a global means of communication. People are interacting in different contexts (while travelling, working, doing business or searching for information) making use of English to achieve their specific goals. Most statistics rank English first among the languages used throughout the world today, with a total number of 1.132 billion users (Ethnologue, 2019). It is among the official languages adopted by both The United Nations and the European Union and is considered the main language of communication among professionals from the fields of science, technology, business, tourism, medicine, banking, diplomacy, where employees across the globe need to cooperate in order to solve various tasks. Within the academic environment, research is often carried out and conveyed in English.

The development of information and communication technology has generated a revolution as regards the possibility to find employment across the world. Employers in different domains, including engineering, are interested in offering jobs to graduates who demonstrate not only technical knowledge, but also at least basic knowledge of English.

Submitted October $1^{\text {st }}, 2020$, accepted for publication November $10^{\text {th }}, 2020$

Corresponding author: Simona Abrudan Caciora. 1 Universitatii Street, Oradea, 410087, Bihor, Romania

| E-mail: veronicaabrudan@yahoo.com 
The requirement to have good communication skills in English rises with each level in the hierarchy of organizations, since many professional projects are now planned and carried out across different countries or regions of the world.

There are a few places in the world where engineering courses are taught in English, for instance Technical University of Denmark or Technical University of Budapest, which presents, in our opinion, a major advantage for graduates. A solid knowledge of English would definitely facilitate graduates' access to jobs in the field of engineering.

The importance of acquiring English language skills, in the case of engineers, was highlighted in studies such as those published by (Reimer, 2002), (Narayan, Pahari, Awasthi, 2015), (Thaky, 2014), (Paraveen and Prasanatha, 2019), or (Latha, 2019). These authors also insisted on the general lack of appropriate communication skills (especially in English) demonstrated by graduates of engineering colleges and on the demanding action of devising syllabuses that are suited to the needs of the job market internationally.

Given the context presented above, we, as teachers of English at technical faculties, decided to help our students understand, from the beginning of their academic education, how important English might be for their future careers. Based exclusively on our subjective perception and experience in teaching English for more than 20 years, we can say that students put little effort in learning English (outside the English class) unless our requirements are very strict, despite the fact they accept that English is important in their development as engineers. Though many students seem to use English in different forms of entertainment (especially games and communication with friends from abroad) - which are excellent ways of improving their linguistic skills, few of them show interest in extra-curricular activities such as the Erasmus program or participation to international projects, if these are not part of compulsory forms of evaluation. In this way, the use of English in more formal contexts is given little practice.

We associate this reluctance to put effort in learning English in formal contexts with students' quite busy schedule at the Faculty of Electrical Engineering and Information Technology. English, being a complementary, though compulsory discipline, is not perceived, in our opinion, as a priority subject. In addition, students seem to slightly disregard the concept of appropriacy and use informal language in all situations. Thus, we feel that it would be a major advantage if we managed to motivate our students to improve their accuracy in using English. At the same time, it would be excellent if we drew the attention of our colleagues upon the important role of teaching English in universities. Starting from such considerations, we decided to highlight the advantage of making use of any context in which our students could practice English. By means of a questionnaire, applied to them during their first semester at the university, we tried to see how students perceive English, its role in the activity of many professionals. We also presented them some of the contexts in which their skills in English might be practiced and developed. We also offered them a description of the requirements (in terms of proficiency in English) expressed by the major employers from Oradea.

We also try to motivate them to take an active part in the activities presented at the English class and presence at these courses. Though we agree that it may be regarded as a rather controversial motivating technique, the use of rewards, in the form of grades, for the activity at each class, has definitely caused a more active and frequent participation of students to all classroom activities (Abrudan \& Sturza, 2017).

In order to attain our goal, we began by asking major employers in the field of engineering from Oradea about the skills they expect to find in a candidate as regards the proficiency in 
English. Our discussions proved to be fruitful ones since they also helped us figure out what parts of our current syllabus we should expand, or what new topics we might include. We realized that the knowledge of technical vocabulary is not the primary requirement, but rather the good command of English, which would allow an employee to interact efficiently in different communication contexts. Thus, we understood that we must give more space to communication-based activities, reproducing the real-life situations in which an engineer or a technician might be involved as part of his/her professional activity.

In addition to considering the future career of our students, we also decided to insist on the importance of developing their English skills in the perspective of getting a scholarship abroad or becoming Erasmus students.

The main purpose of this paper is to show the steps we took towards attaining our goals. Our first aim was to emphasize the importance of mastering communication skills in English in the case of engineering students, in order to improve both their academic performance and the chances to pursue a career in the field of engineering. Secondly, we intended to highlight the importance of teaching English in universities.

The following sections of this paper will present:

a. Contents of the current English course at the Faculty of Electrical Engineering and Information Technology, University of Oradea;

b. Language skills required by several major employers of engineers in the region of Oradea;

c. The results of a questionnaire, applied to the first year students of the Faculty of Electrical Engineering and Information Technology, University of Oradea, with the view of increasing their awareness of the important role of English for their future careers as engineers;

d. Our conclusions, based on the results obtained.

\section{BACKGROUND OF THE STUDY}

\subsection{The content of the English course at the Faculty of Electrical Engineering and Information Technology, University of Oradea}

At the University of Oradea, Faculty of Electrical Engineering and Information Technology, the students have the opportunity to study English during the first two years of undergraduate studies (four semesters, one hour per week in most cases). Otherwise, English is not used as a medium of communication in the lectures, seminaries, laboratories or tutorials related to engineering subjects. English is a compulsory subject in the curriculum, but it is defined as a complementary discipline.

The materials we use are mostly the result of our collaboration with colleagues who are experts in different subjects taught at the Faculty of Electrical Engineering and Information Technology, which resulted in the publication of books addressed to the students who take part to our English course. We also use other published materials.

As regards the contents of the course, the emphasis is placed on teaching vocabulary related to the field of engineering in general (during the first year of study) and to the specialization chosen by the students (Computer Science, Information Technology, Control Systems, Electrical Engineering, Electrical Systems, Applied Electronics, Software and Networks for Telecommunications, Economic Engineering). At the English courses taught 
during the first year of undergraduate studies, the vocabulary is introduced in three main ways:

(a) before reading/discussing contexts in which technical vocabulary is encountered (the terms may be written on the blackboard and explained and translated, presented as part of a glossary or presented in sample sentences while students are encouraged to explain them);

(b) while reading texts (the concepts may be defined as part of the text itself).

The reading sections are followed up by exercises in which technical vocabulary is repeated when students complete fill-in exercises, answer text-related questions, interpret graphs, figures, or other forms of visual information. Students are also encouraged to use the technical concepts discussed during the class in sentences of their own or to try to explain in what practical contexts the theoretical aspects discussed in the reading section can be encountered. Each class ends with an exercise in which students have to role-play a situation that relates to the application of the technical issue discussed in real life.

During the second year of undergraduate study, the English classes focus on concepts related to students' chosen branch of engineering, and the activities rely more on listening and speaking.

The presentation above shows that little class space remains available for discussing grammatical issues or focusing on communication in real-life situations. Another problem relates to lack of uniformity (within groups of students) as regards students' ability to use basic English. In our opinion, these are major drawbacks, to which we try to find efficient solutions.

In this study we shall focus on our perception that the syllabus of the English course, taught at the Faculty of Electrical Engineering and Information Technology, University of Oradea, should be reformed and adapted so that students might become better prepared for meeting the demands of the current job-market in the region of Oradea. The first step we made in this respect was to contact the members of the Human Resources Departments of the following multinational companies: Celestica, Inteva, Plexus and Nidec. In Oradea, engineering students are invited, from the very first year of their academic education, to visit some of the multinational companies located in the Industrial Park of Oradea. The students of the Faculty of Electrical Engineering and Information Technology, University of Oradea, usually do their practice, internship stages or get jobs in multinational companies such as Celestica, Plexus, Inteva, Comau, Nidec, and Faist Mekatronic. We sent an e-mail informing them on our intention to improve our syllabus and adapt it to their requirements. In two cases, we received prompt answers and established a basis for future collaboration. We shall present below the result obtained.

\subsection{Language skills required for employees by some major multinational companies in Oradea}

Though employees of most multinational companies referred to in the previous section operate with technical concepts in their activity, knowledge of technical jargon is not considered crucial for employment. This is due to the fact that the acronyms or concepts used may be learned quite easily if employees have a good command of general English. Thus, knowledge of at least basic English is considered a necessity, starting from the level of technician, and increasing as positions go higher in the structure of the company. 
Generally, for the level of production operator, English is not a requirement since only simple commands and answers would involve the use of English by an employee. However, communication with production operators during audits would be more efficient if even at this level the employees would be able to use English efficiently. Thus, A1 level of knowledge of English represents an advantage during the employment process.

For technicians, A2 level of proficiency in English is required. In their case, interactions within the job-related environment would include answering customers questions, communicating with suppliers, answering questions raised during audits.

Engineers are required to demonstrate at least a $\mathrm{C} 1$ level of using English since their activity encompasses extensive communication with customers, co-workers or persons from outside the company. An engineer might be required to demonstrate ability to understand long, context-related texts and recognize implicit meaning, express ideas fluently and spontaneously, produce clear, well structured written or verbal discourse. Activity generally includes reading procedures and documents, writing reports, writing letters, communicating (in writing or verbally) with co-workers or visitors from within or outside the company, providing information during audits.

In conclusion, English is used for formal or official communication (the headquarters of the above-mentioned companies are abroad). Employees need to prepare various kinds of written documents (letters, reports, proposals, make presentations of products and components.

Effective oral communication skills include: presentations, negotiating, conflict resolution, knowledge-sharing: Their writing skills might help them produce efficient reports, proposals, instruction manuals, memos, official correspondence.

\section{THE RESUlts OF THE QUESTIONNAIRE APPLIED TO THE FIRST YEAR STUDENTS OF THE FACULTY OF ELECTRICAL ENGINEERING AND INFORMATION TECHNOLOGY, UNIVERSITY OF ORADEA}

\subsection{Language skills required for employees by some major multinational companies in Oradea}

As indicated in the previous sections of this paper, our intention is to improve our efficiency in teaching English for the engineering students studying at the Faculty of Electrical Engineering and Information Technology, University of Oradea, so as to increase their chances of obtaining a good job in the field. The first step towards the materialization of our intention was our attempt to increase students' awareness as regards the important role played by the English language during the process of their employment as technicians or engineers in the multinational companies in Oradea. We started from the assumption that students might not be aware of the important role played by English in their future career as engineers. By raising their awareness in terms of the importance of English for their future career, we also wanted to increase their motivation to participate actively at the English classes.

As a result of our assumptions, we devised a questionnaire, which was applied to the first year engineering students at the Faculty of Electrical Engineering and Information Technology, University of Oradea. We chose the students of the first year because we wanted to increase their motivation to learn English. In addition, as part of our collaboration with the multinational companies that offer training programs to our students, we wanted to 
draw their attention, as early as possible, upon the benefits of improving their English skills. However, the fact that students are still during an early stage of their academic education might mean that they are not very familiar with the academic context and thus have not understood yet how important it is to take advantage of any opportunity to learn and develop, which is offered to them as part of their academic education.

The questionnaire was applied in December 2019 and not at the very beginning of the academic year, since we wanted to give students time to become familiar with the syllabus of the English course, the development of the classes, and the contexts in which they might use English outside the English class. A number of 170 students agreed to answer the questions. The questionnaires were distributed to students and they had one hour available to give their answers. The students did not write their names on the papers.

\subsection{Results interpretation}

The questionnaire we devised included 10 items. It started with a general question, challenging students to define a global language (Q1. How would you define a global language?), and continued with an item in which they were invited to agree or disagree with the idea of English being a global language, and explain the reason for it being so, in case they chose the positive answer. The second item was a yes/no question type (Q2. Do you think that English might be considered a global language? a. If yes, explain why. b. No.)

In terms of the definitions given by students to a global language, most associated it with a large number of active users all over the world; it was also defined as a language that is used in many domains, so as to facilitate communication across countries and nations.

To the second question, all students interviewed choose the first answer alternative, defining English as a global language for reasons such as its accessibility (you can hear it spoken almost everywhere, it is taught in most schools across the globe). Some students considered it a language that is easy to learn (it is used in so many contexts and situations that somehow people are quite familiar with some words and structures, even if they do not study it). In addition, they associated its statute of a global language with the fact that it is the official language in the USA or Great Britain, two strong economic powers. Other students indicated the fact that technology unites the world today and since most technological explanations are in English, this situation contributed even more to increasing the number of users across the world. Music, movies, games and other forms of entertainment are some other means that help/motivate one learn English.

The following five questions referred to students' involvement in activities that would make them use or improve their skills of communicating in English. They were meant, in addition to elicit answers from students, to draw their attention upon those situations that might provide them with opportunities to use English actively. Thus, question 3 (another yes/no question) asked students whether English is used as a means of communication outside English classes (during other lectures, laboratories, or projects) - Q.4. While being a student at the University of Oradea, have you used English as a means of communication for any lecture, seminar, laboratory or project - other than the English class? a. Yes - 141 students; b. No - 29 students.

As seen from the numbers above, most students agreed upon the fact that English is used as a means of communication for different activities they do - lectures, seminars or laboratories. However, at least as far as we know, English is not used for conveying information during class activities at the Faculty of Electrical Engineering and Information 
Technology, University of Oradea. We assume that, in giving an answer to these questions students considered the fact that since much software or commands (when using the computer) are in English they have been using English during other lectures, laboratories or project-related activities. We should point out here that most subjects taught at our faculty relate to learning the use of computer software for different applications, in the fields of Electrical Engineering, Telecommunications, Electronics and Computer Science.

Item 4 (While being a student at the University of Oradea, have you employed English in order to do research - have you watched tutorials in English/read materials written in English/communicated with peers or specialists in the field, using English?) was another yes/no question. Most students said they use English for research-related activities, though it was a yes/no question, some of them added to the 'yes' answer that most of the material they read/view/listen to for doing further research in the field is in English. From among the ones who chose the negative answer, some explained that they are only in the first year and thus they have not done much extra research, or explained that they do not know English very well and so they did not use it for research. As indicated previously, one of the limitations of this study relates to the fact that students are only at the beginning of their academic studies and probably are not very familiar with the way they should do research. To this question 153 students replied affirmatively and 17 students replied 'No'.

Question 5 asked students whether they accepted any challenge to use English while being a student at the University of Oradea. If they answered yes, they were asked to explain when they used English. The other answer alternative was No. Q.5. Did you accept any challenge to use English while being a student at the University of Oradea, Faculty of Electrical Engineering and Information Technology? a. If yes, in what context? (Give details) b. No. Though prior to starting answering the questions, these were explained the students, it seems that this question was not formulated clearly enough and we did not emphasize those other contexts. For these reasons, some of the answers were not so relevant, in our opinion. Some students merely opted for the yes/no answer, without explaining their choice, or when the affirmative answer was chosen, students did not write about the contexts in which they were challenged to use English, but rather their opinion that accepting possible challenges to use English would definitely be helpful to them. The answers are as follows: 108 students replied positively, 62 students replied with a negation.

Since the students are in their first year at the university, many of them did not have opportunities outside the English class to use English. Of the 62 students who answered negatively, 11 associated their negative answer with their lack of confidence in using English, while the rest of 51 students mentioned the lack of opportunity to use English.

From among the 108 students who chose the affirmative answer, 6 chose the yes answer without giving any argument. Two respondents mentioned presentations of projects while being students at another faculty. One student mentioned the use of English during an interview. Twenty students spoke of interactions with Erasmus students. Twenty eight students associated their use of English either with their faculty-related subjects (such as programming, for instance), or with talking with their colleagues about technologyrelated things. Finally, there were 30 students who mentioned using English while making presentations or giving arguments during the English class.

Question 6 inquired about students' interest in studying abroad, which would also require them, in most cases, to be able to use English in an academic context. Based strictly on personal observation over time, we have seen little interest on the part of the Romanian students in relation to this aspect. The first explanation in this respect would 
be lack of confidence and unwillingness to accept the challenge, followed by the idea that students do not have enough money to support their attempt, and third, students mentioned their inability to use English in an academic context. The answers given by the students who answered our questionnaire show, nevertheless, quite a high interest in learning in another country. Total of 119 students gave an affirmative answer, meanwhile 51 students replied with a negative one.

As regards their interest in standardized tests, students at the Faculty of Electrical Engineering and Information Technology presented much interest during our class conversations, though few of them have actually taken such tests, as shown by the results obtained at question 7 - Q.7. Did you take up any standardized test in order to demonstrate your proficiency in English? a. 61 students replied 'yes'; b. 109 students replied 'no'.

We believe that the number of students at the Faculty of Electrical Engineering and Information technology having passed standardized tests may be even lower, based on our conversations with the students, at the beginning of our classes. We assume that some students might have considered their school leaving examinations (where some of them were evaluated at English) as standardized tests, which is not accurate.

However, in terms of interactions with peers, or as regards the use of English as part of students' social life, it appears that a large number of students actually use this language. At question 8 - Q. 8. Do you use English as part of your student's social life?, most of the students who took part to the survey chose the positive answer, namely 132 positive replies and 38 negative replies.

The last two questions were aimed at evaluating students' perception as regards the importance of knowing English, in the perspective of a future career in the field of engineering. Question 9 - Q. 9. For my future career as an engineer, English is: a. Very important; b. Important; c. Quite important; d. Not very important; e. Not important at all, looked at the degree of importance attributed by students to the knowledge of English in the context of a possible career as engineers. Their answers reflected that most students perceive English as having an important role to play in their future career. Thus, 92 students considered English as being very important, 61 students appreciated it as being important and 17 students regarded it as quite important. No student considered that knowledge of English is not very important or not important at all for their future career.

Question 10 looked at students' expectations as regards the contexts in which English might be required if they would become engineers, especially if they got employed in a multinational company - Q. 10. In what types of verbal/written interactions you expect you might be involved if you got a job as technician/engineer in a global company. Most students said they would expect to use both written and verbal English in activities such as: reading technical explanations (16 students) and using technical concepts (8 students); making presentations (19 students); team work and collaborating with colleagues (peers or CEOs) (20 students); explaining processes and giving instructions (9 students); during the process of getting a job (3 students); while using different software (3 students); during the process of negotiation ( 2 students); making phone conversations ( 3 students); communicating with customers from abroad (6 students); during audits (3 students); while writing e-mails (12 students); writing reports (2 students).

After completing the questionnaire, the students were presented with a description of the communications skills generally required by the multinational companies offering jobs in Oradea, included in section 2.2. of this paper. Thus, they could correlate their answers to question 10 with the suggestions expressed by the representatives of two major multinational 
companies in Oradea. Our aim was to draw their attention upon the expectations of employers in the field as regards their proficiency in English.

\section{CONCLUSIONS}

This paper aimed to emphasize the importance of mastering communication skills in English in the case of engineering students, in order to improve both their academic performance and the chances to pursue a career in the field of engineering. In addition, we wanted to highlight the importance of teaching English at universities and of adapting syllabuses to the ever-changing international job market.

In order to attain our aims we started from analyzing the content of the English course at the Faculty of Electrical Engineering and Information Technology, University of Oradea, and continued by correlating it with the requirements of the major employers of engineers, located in or around Oradea. As a result of our collaboration with the Human Relations specialists from companies such as Celestica and Inteva, we realized that we should include more communication-based activities that would help our students role-play real-life contexts. Such contexts might include: taking part to an interview, talking to co-workers or superiors, answering questions during an audit, describing processes and designs, describing technical functions and applications, discussing technical problems and/or technical requirements, writing reports, letters, e-mails, making effective phone-conversations.

In order to help students function more efficiently in the academic context, it would be helpful to insist on presenting them with efficient methods of filling in application forms, discussing vocabulary related to the academic environment, developing skills of structuring an argument, planning and completing a piece of writing, analyzing data.

As regards the evaluation of the questionnaire, it emerged clearly that most students agree upon the important role of English, which has become a lingua franca in many domains of activity, including that of academic research. They also agree that good command of this language would open them better possibilities to get a scholarship or work in a multinational company. However, they are still rather passive in terms of using it. Most of them use it especially in contexts when they are required to do so (during English classes, or when having to interact with foreign students). Though some of our students argue they feel at ease when using English, many others are still unsure about their capacity to express themselves freely and do not look for opportunities to use it.

We believe that by using questionnaire with students, and by presenting them with the requirements of the major employers in the field, we fulfilled our aim of increasing their awareness as regards the need to put effort in improving their skills in using English and develop positive attitudes towards learning this language. We also understood how the syllabus might be adapted so as we can provide students with the opportunity to develop communication skills in English that are in accordance with the requirements of the employers in the field of engineering. 


\section{REFERENCES}

Abrudan Caciora Simona, Sturza Amalia Journal of Teaching English for Specific and Academic Purposes, ISSN 2334-9182 (Print) 2334-9212 (Online), Vol 5, No. 2 2017, pp. 295-307

Ethnologue, 22 ${ }^{\text {nd }}$ edition, published by SIl International, USA, 2019, found at https://en.wikipedia.org/wiki/List_of_languages_by_total_number_of_speakers, last accessed on $26^{\text {th }}$ of January, 2020.

Kumar Paraveen, Kumar Prasanatha, The role of English and the Importance of Communication to the Mechanical engineering Students, International Journal of Mechanical Enginerering and Technology, Volume 9, issue 9, sept. 2019, pp, 782-788

Latha, K., The Role of English Language for Engineering Students, in American International Journal of Research in Humanities, arts and Social Sciences, ISSN (Print) 2328-3734, ISSN online 2328-3696, available at http $>/ / \mathrm{www}$.isir.net, last accessed on $8^{\text {th }}$ of December 2019, pp. 122-123

Reimer MJ, English and Communication Skills for the Global Engineer, Global Journal of Engineering Education, Vol. 6, No.1, Published in Australia, 2002.

Shresta Rup Narayan, Bharat Raj Pahari, Jai Raj Awasthi, Impact of English on the Career of Engineering Students: A Brief Overview in G(local) Context, in Journal of Institute of Engineering, 2015, 11 (1), 182-188.

Thaky P (2014), Importance of English and Communication skills for Technical Professionals.

International Journal of Scientifc Research. Volume 3 (Issue 4), April, 2014: 211. 